\title{
OBSERVATIONAL NEEDS OF DYNAMIC GREEN OCEAN MODELS
}

\author{
Corinne Le Quéré(1), (2) , Shubha Sathyendranath ${ }^{(3)}$, Meike $\operatorname{Vogt}^{(4)}$, Erik. T. Buitenhuis ${ }^{(1)}$, Laurent Bopp ${ }^{(5)}$, \\ Scott Doney ${ }^{(6)}$, Stephanie Dutkiewicz ${ }^{(7)}$, Richard J. Geider ${ }^{(8)}$, Sandy Harrison ${ }^{(9)}$, Christine Klaas ${ }^{(10)}$, \\ Louis Legendre ${ }^{(11)}$, Stéphane Pesant ${ }^{(11)}$, Trevor Platt ${ }^{(3)}$, Colin Prentice ${ }^{(12)}$, Richard Rivkin $^{(13)}$, \\ Dieter Wolf-Gladrow $^{(10)}$, Yasuhiro Yamanaka ${ }^{(14)}$ \\ ${ }^{(1)}$ School of Environment Sciences, University of East Anglia, University Drive, Norwich, NR4 7TJ, UK, \\ Email: c.lequere@uea.ac.uk; \\ (2) British Antarctic Survey, High Cross, Madingley Road, Cambridge BC3 OET UK;

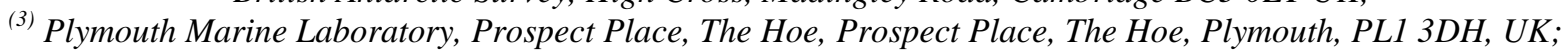 \\ Email:ssat@pml.ac.uk; treatt@pml.ac.uk \\ (4) Institute for Biogeochemistry and Pollutant Dynamics, ETH, Zürich, CHN E23.2, University Str. 16, CH-8092 \\ Zurich, Switzerland; Email: meike.vogt@env.ethz.ch \\ ${ }^{(5)}$ Lab. des Sciences du Climat et de l'Environnement, Orme des Merisiers, Bat. 709, F-91191 Gif-sur-Yvette, France; \\ Email: laurent.bopp@lsce.ipsl.fr \\ (6) Woods Hole Oceanographic Institution, Clark 424, MS\#25, Woods Hole, Ma 02543, USA; Email: sdoney@whoi.edu \\ (7) Massachusetts Institutes of Technology, 77 Massachusetts Av. Cambridge, MA 02139-4307, USA \\ Email: stephd@mit.edu \\ ${ }^{(8)}$ Dept.for Biological Sciences, Univ. of Essex, Colchester CO4 3SQ,UK; Email: geider@essex.ac.uk \\ ${ }^{(9)}$ School of Geographical Sciences, Univ. of Bristol, University Road, Bristol BS8 SS, UK; \\ Email: sandy.harrison@bristol.ac.uk \\ ${ }^{(10)}$ Alfred Wegener Institute for Polar and Marine Research, Am Handelshafen 12, D-27570 Bremerhaven, Germany; \\ Email: Christine.Klaas@awi.de; Dieter.Wolf-Gladrow@awi.de \\ ${ }^{(11)}$ Laboratoire d'Océanographie de Villefranche, B.P. 08, Villefranche-sur-Mer, 06238 Cedex, France \\ Email: louis.legendre@obs-vlfr.fr \\ ${ }^{(12)}$ QUEST (Quantifying and Understanding the Earth System), Dept. of Earth Sciences, Univ. of Bristol, Queen's Road, \\ BS8 1RJ, UK; Email: colin.prentice@mq.edu.au \\ ${ }^{(13)}$ Ocean Sciences Centre, Memorial Univ., St. John's, Newfoundland A1C 5S7, Canada; Email: rrivkin@mun.ca \\ ${ }^{(14)}$ Graduate School of Environmental Earth Science, Hokkaido Univ., Kita 10, Nishi 5, Kita-ku Sapporo 060-0810, \\ Japan.Email: gakujutu@ees.hokudai.ac.jp
}

\begin{abstract}
The numerical modelling community is an important user group of ocean observations requiring data of global coverage for model parameterisation and evaluation. Dynamic Green Ocean Models (DGOMs) are a class of ocean biogeochemistry models that represent various types of plankton with distinct functions in food webs and biogeochemical cycles. DGOMs are used to study the feedbacks between climate and ocean biogeochemistry, particularly those mediated by ecosystem dynamics that influence $\mathrm{CO}_{2}$, DMS, and $\mathrm{N}_{2} \mathrm{O}$ fluxes to and from the atmosphere. DGOMs require experimental data for the parameterization of plankton growth and loss rates and of ecological interactions, and a range of observations for their evaluation. The most urgent data needs are: (1) decadal trends in surface ocean $\mathrm{pCO}_{2}$ and subsurface $\mathrm{O}_{2}$, (2) biomass (in carbon concentration) and (3) growth rates as a function of temperature for the important plankton types, and (4) sinking flux of particulate organic carbon. A global coverage is essential to evaluate the model mean state. Repeated measurements for all seasons are most useful to evaluate the model response to environmental change.
\end{abstract}

These data can be obtained by a combination of platforms, including remote sensing, repeat sections and gliders, and oceanic and atmospheric time-series stations.

\section{INTRODUCTION}

Dynamic Green Ocean Models (DGOMs) are a new class of models that strive to represent more realistically the biota that influence and in turn are influenced by global biogeochemical cycles [7], [5]. DGOMs explicitly represent various types of plankton that have distinct functions in food webs and biogeochemical cycles. DGOMs were originally built to help understand how marine ecosystems respond to climate change, and how ocean biogeochemistry, particularly biological feedback mechanisms, may modulate climate change [7]. Such models are designed to project the future state of the marine ecosystems and ocean biogeochemistry under various climate-change scenarios. They can contribute to addressing the following questions:

- What are the impacts of climate change and ocean acidification on ocean biogeochemistry and marine ecosystems? 
- What are the potential feedbacks to climate?

- What is the role of marine biodiversity for ocean biogeochemistry and climate?

- Are there extensive and unanticipated climate changes associated with changes in marine ecosystems?

As sustained global ocean observations begin to incorporate biological elements, it is worth considering whether the observations can be geared to meet the needs of modellers. The ocean community relies on synergy between observations and models to obtain as complete a view of the ocean ecosystems and their functions as possible. In this paper, we examine the most pressing observational needs from the perspective of Dynamic Green Ocean Models, and how they may be met by various elements of the ocean observation systems.

\section{SOME IMPORTANT PLANKTON FUNCTIONAL TYPES}

We begin by providing a brief overview of the major marine plankton groups that are currently recognized and implemented in DGOMs. Planktonic organisms in DGOMs are often grouped based on their biogeochemical or biological impact in the ecosystems into Plankton Functional Types (PFTs). Ideally, the PFTs defined in models do not overlap and include all major groups from a biogeochemical perspective. In practice, the most recognized phytoplankton PFT groups are the diatoms, coccolithophores, Phaeocystis, nitrogen fixers and picophytoplankton. In addition, DGOMs recognize several PFTs for heterotrophs, including pico-heterotrophs (bacteria and Archaea) and various types of zooplankton based primarily on size and associated grazing rates as well as feeding preferences (proto, meso and macro zooplankton).

Diatoms use silica to produce external cell walls or frustules, thereby engaging in the oceanic silica cycle. Diatoms form large blooms that produce fast sinking aggregates, when nutrients are exhausted. Hence diatoms are considered to be major contributors to carbon and silicon export into the deep ocean and sediments. Coccolithophores use dissolved calcium and carbonate ions in the water to produce calcium carbonate. At the same time, the calcification process leads to a decrease in alkalinity and an increase in the partial pressure of carbon dioxide in the water. Calcium carbonate platelets known as coccoliths cover the cells, and in some species, are also partly released in the surrounding water. The release from the cell and subsequent sinking of coccoliths removes both calcium and inorganic carbon from the surface waters, and may also act as ballast that contributes to the rapid sinking of organic and inorganic material from the surface to the ocean interior.

Some groups of phytoplankton are known to be a major marine source of dimethylsulfoniopropionate (DMSp) a precursor to dimethyl sulphide (DMS). DMS is released into the atmosphere where it can be oxidized to form cloud condensation nuclei, thus impacting cloud formation and the Earth's radiation budget. DMSp is found in a variety of phytoplankton groups: Phaeocystis and coccolithophores, dinoflagellates, chrysophytes, pelagophytes and prasinophytes. Only one phytoplankton group is able to use dissolved nitrogen $\left(\mathrm{N}_{2}\right)$ as a nutrient source as opposed to oxydised or reduced nitrogen in the water, hence phytoplankton species belonging to the cyanobacteria (also known as blue-green algae), are classified as nitrogen fixers in DGOMs. Picophytoplankton, whose main characteristics is their small size (diameter less than $2 \mu \mathrm{m}$ ), are a diverse group that include both eukaryotes and prokaryotes (belonging to the domains of Eucaryota and bacteria), considered to be important players in recycled production in the ocean. These picoplankton include cyanobacteria (mostly in the genera Synechococcus and Prochlorococcus), but unlike the nitrogen fixers, they rely on nitrate, nitrite or ammonium.

Most of the PFTs, with the notable exception of picophytoplankton, are known to form extensive blooms in the ocean. Conversely, in pelagic systems, the picoplankton is present the whole year round, shows little biomass variations and it dominates primary production in oligotrophic systems. That includes the subtropical gyres, High Nutrients Low Chlorophyll (HNLC) areas as well as winter and summer communities in temperate and coastal areas.

Heterotrophs are major contributors to ocean biogeochemistry and contribute to calcium carbonate precipitation and DMS production. Pico-heterotrophs (bacteria and Archaea) break down dissolved and particulate detrital organic matter and thus contribute to the recycling loop. Zooplankton generally eat phytoplankton and the heterotrophs that are smaller than themselves. Both food intake and loss rates decrease with size. Thus, the activity of zooplankton decreases faster than the biomass in successive trophic levels. Zooplankton are also distinguished by their different formation of protective shells, with some organisms developing organic scales (dinoflagellates, some ciliates, crustaceans) or calcium carbonate shells (pteropods, foraminifera). Protozooplankton mainly represent nanoflagellates, ciliates, and heterotrophic flagellates. Protozooplankton have high growth rates and dampen the formation of spring blooms. Mesozooplankton mainly represent copepods. They 
produce large and fast-sinking fecal pellets that contribute to the export of organic matter to the ocean interior. Macrozooplankton mainly represent euphausiids, salps, appendicularians and pteropods. These organisms all produce fast-sinking fecal pellets and graze across a wide spectrum of sizes.

Several PFTs could be further split into multiple groups. For instance, foraminifera or pteropods produce shells of calcium carbonate and radiolaria produce shells of silica, both of which have specific effects on ocean biogeochemistry. The various organisms included in the macrozooplankton group above have different growth rates, feeding habits, shell protection and carbon density. The growth and loss rates of some phytoplankton (e.g. Phaeocystis) are different if they are present in single cells or colonies. These are not explicitly represented in current models, because too little is known about their ecology, abundances and physiological rates. Such groups do not tend to build up large biomasses or are present in large numbers only intermittently, but can have significant impact on biogeochemical cycles locally. See table in [11] for a summary of various phytoplankton functional types.

All of these organisms respond to changes in temperature. Some are vulnerable to ocean acidification, and some are the principal food for commercially important fish. In addition to their roles in the global biogeochemical cycles, PFTs are also relevant when ecosystems are considered in the management of marine resources. Thus, the evaluation of the impact of climate change on the marine ecosystem requires that we examine the performance of these different types of organisms under different environmental conditions. Modelling is an essential tool to evaluate ecosystem-climate interactions, but models depend on various types of observations for their initialization, parameterisation and evaluation.

\section{DATA REQUIREMENTS FOR DGOMS}

Global ocean biogeochemistry models have been used for about 20 years. They have been developed essentially based on geochemical data. Now that models include a more specific representation of ecosystems and begin to produce results on climateecosystem interactions, it is essential that adequate data is available for model parameterization and evaluation. As DGOM are still in the early phases of their developments, it is an ideal time to co-ordinate the data and modelling efforts.

All global ocean biogeochemistry models require oceanographic data about basic physical and chemical variables, such as temperature, salinity, mixed layer depth, and macro-nutrient concentration. Most models also require f-nutrients such as iron. Models addressing the evolution of the oceanic $\mathrm{CO}_{2}$ sink require primarily the partial pressure of $\mathrm{CO}_{2}\left(\mathrm{pCO}_{2}\right)$ at the surface, and column inventories for dissolved inorganic carbon (DIC), alkalinity, and dissolved oxygen $\left(\mathrm{O}_{2}\right)$. Oxygen data are useful because it is influenced by changes in both ocean physics and in marine ecosystems, but unlike $\mathrm{CO}_{2}, \mathrm{O}_{2}$ is not influenced by the gas increase in the atmosphere. Thus, $\mathrm{O}_{2}$ can be used to identify the ocean interior processes (physical, chemical or biological) driving the modelled behaviour. In addition, low $\mathrm{O}_{2}$ concentrations are particularly important for the production of biogenic gases such as $\mathrm{N}_{2} \mathrm{O}$. Models addressing ocean acidification require further carbonate chemistry variables: $\mathrm{pH}$, carbonate ion $\left(\mathrm{CO}^{2-}\right)$, and bicarbonate ion $\left(\mathrm{HCO}_{3}^{-}\right)$concentrations, which can be computed using temperature, salinity and data from any pair of the seven carbonate chemistry variables mentioned above (see Schuster et al., 2010). Dissolved organic matter is a major carbon reservoir closely involved in microbial dynamics and is needed as basic evaluation data for most ocean biogeochemistry models. A reasonable representation of the global cycles of carbon, oxygen and nutrients including their spatial distribution and temporal variability is essential to all ocean biogeochemistry models used to address climate-related questions.

DGOMs have additional data requirements specific to plankton physiology and ecology. Field and experimental data are essential to constrain biological synthesis of organic matter (OM) from inorganic matter (e.g. uptake of carbon, dinitrogen and nutrients), and of biogenic inorganic matter (e.g. calcification and silicification). Experimental data are also needed to constrain the physical, chemical and biological transformations of OM (e.g. aggregation, disaggregation, grazing, egestion, exudation, mortality, lysis), the segregation of OM (e.g. production of refractory OM, horizontal and vertical export), and the remineralisation (e.g. respiration).

DGOMs require experimental data describing the functional response of PFTs to environmental conditions These include: (i) growth (or grazing) rates as a function of temperature, light, nutrients or food concentrations, (ii) calcification, silicification, and nitrogen fixation, (iii) foraging strategies and food preferences (for zooplankton), (iv) respiration and mortality rates, (v) the export and chemical composition of the biogenic matter sinking out of the surface layer, (vi) and process studies on ecosystembiogeochemistry interactions. At present, many of these rate parameters are poorly constrained in DGOMs. Taxon- or class-specific photosynthetic rate parameters are not generally measured in the field, 
though it would be ideal from a modelling perspective. Models are particularly sensitive to the parameterization of growth rates, loss processes, and to the sinking speed of organic matter. The availability of these data is currently not sufficient to directly constrain the PFT evolution and dynamics in models (Tab. 1).

DGOMs also have additional data requirements specific to the evaluation of their PFT components. For DGOMs, specific evaluation of the model output consists of the comparison of global distributions of carbon biomass for its various PFTs and the fluxes between PFTs. Unfortunately, most plankton observations are reported as presence/absence, abundances or pigment concentrations, which need to be converted to carbon biomass. These conversions are not trivial and carbon ratios vary greatly among organisms, with their physiological state and with environmental conditions. Therefore, in order to obtain accurate observations of carbon biomass, one must avoid using general conversion factors and use instead, as much as possible, the taxonomic composition within each PFT and complementary data such as the wet/dry weight, size, biovolume and carbon content. Both PFT biomass and flux rates vary considerably so that it is important to gather field observations of these variables in different regions, throughout the water column, and during all seasons.

Technological advances have made possible the routine measurement of many biological properties of interest. These include: (i) absorption characteristics of phytoplankton (essential in computations of light penetration and in models of photosynthesis), (ii) particulate organic carbon, nitrogen and phosphate, and the dissolved counterparts, particulate inorganic carbon and biogenic silica (for comparison with model output), pigment measurements by High Performance Liquid Chromatography (HPLC; for diagnosing phytoplankton functional types), (iii) flow cytometric measurements (for enumerating PFTs), (iv) photosynthesis-irradiance parameters in situ (for computations of primary production, both in models and by remote sensing), and (v) benchtop imaging systems for plankton identification, size and biovolume determination. Other measurements (grazing, respiration) are costly and complex and are difficult to make on a routine basis. No single type of platform would be able to meet all the data requirements of DGOMs (Tab. 1). We discuss how the requirements may be best met through the use of a variety of platforms and approaches.

\subsection{Experimental Data}

Laboratory data are needed to estimate specific parameters needed to build DGOMs (see main text and Tab. 1). Other experimental data are also needed to improve our knowledge of plankton ecology. Targeted experiments can be done in laboratory environments to estimate the response of individual species to a range of environmental conditions. Mesocosm and field experiments are also particularly useful to assess the response of plankton communities to changing environmental conditions.

\subsection{Remote Sensing}

Remote sensing of ocean colour is a valuable source of data for the evaluation of DGOMs. Standard products such as chlorophyll distribution can be used to examine whether the modelled total phytoplankton concentration is realistic. Similarly, total primary production fields can be compared with satellitederived productivity products, but the latter are not yet always robust enough to use for validation of DGOMs [3]. Furthermore, recent developments in remote sensing now make it possible to map dissolved and particulate organic matter [10] and [15] and the presence of several phytoplankton functional types (e.g., diatoms, coccolithophores, picoplankton) from space [11]. It has been shown that satellite data can be used to map fields of many ecological indicators (e.g. the timing of the spring bloom), as listed in [13], which also would be useful for testing model outputs. The recent IOCCG report [6] provides an extensive review of ocean-colour products, many of use to modellers. In climate-related studies, and especially for use in DGOMs, it is important to have a continuous, consistent, and uninterrupted stream of ocean-colour data that extends over several decades.

Satellite observations are not adequate to meet all the data requirements of DGOMs: not all biological and physical variables are amenable to remote sensing, and furthermore, remote sensing is unable to provide the necessary information on the vertical structure in biological and biogeochemical properties. Further in situ data are required to develop and validate satellite algorithms themselves. We next examine how various in situ platforms can be used to meet the data requirements of DGOMs.

\subsection{Repeat Sections}

By their very nature, fixed-point time series stations are not able to provide spatially-extensive data. The 
collection of the full suite of data of relevance to DGOMs can at present only be achieved from ships, and hence, additional sections by ships are also essential to obtain global coverage. Full water column sampling of DIC, $\mathrm{O}_{2}$ and nutrients every 10 years on a core network of lines is needed to determine the causes of changes. Other useful efforts for gathering data to evaluate DGOMs include the continuous plankton

[OTS: time series;

coverage $^{11} \quad$ priority $\quad$ ATS: atmospheric time series; SEC: repeat sections;

SAT: remote sensing;

B\&G: Buoys and Gliders]

\section{Parameterisation data}

Growth rate for all PFTs:

\section{with temperature}

with resources (incl. preference and

threshold)

with light (for phytoplankton)

Loss rates for all PFTs

with temperature

\section{Evaluation data}

\begin{tabular}{l} 
global cycles \\
\hline surface $\mathrm{pCO}_{2}$ \\
DIC,TALK, $\mathrm{pH}^{4}$ \\
$\mathrm{DMS}$ \\
$\mathrm{N}_{2} \mathrm{O}$ \\
sub-surface $\mathrm{O}_{2}$ \\
$\mathrm{~N}, \mathrm{P}, \mathrm{Si}$ \\
$\mathrm{Fe}$ \\
biomass (or related) \\
\hline total chlorophyll \\
diatoms \\
coccolithophores \\
Phaeocystis \\
$\mathrm{N}_{2}$-fixers \\
picophytoplankton \\
bacteria and Archaea \\
protozooplankton \\
mesozooplankton \\
macrozooplankton \\
ecosystem fluxes \\
primary production \\
secondary production \\
POC export \\
CaCO
\end{tabular}

\begin{tabular}{|c|c|c|}
\hline $\begin{array}{l}\text { fair } \\
\text { poor }\end{array}$ & $\begin{array}{c}\text { high } \\
\text { medium }\end{array}$ & $\begin{array}{l}\text { experimental data } \\
\text { experimental data }\end{array}$ \\
\hline poor & medium & experimental data ${ }^{2}$ \\
\hline fair & low & experimental data ${ }^{2}$ \\
\hline
\end{tabular}

$\begin{array}{ccl}\text { good } & \text { high } & \text { OTS, SEC, B\&G, ATS } \\ \text { good } & \text { low } & \text { OTS, SEC, B\&G } \\ \text { fair } & \text { low } & \text { OTS, SEC } \\ \text { fair } & \text { low } & \text { OTS, SEC } \\ \text { good } & \text { high } & \text { OTS, SEC, B\&G, ATS } \\ \text { good } & \text { low } & \text { OTS, SEC, B\&G } \\ \text { fair } & \text { low } & \text { OTS, SEC }\end{array}$

\begin{tabular}{|c|c|c|}
\hline very good & high & SAT, OTS, SEC, B\&G \\
\hline poor & high & SAT, OTS, SEC \\
\hline poor & high & SAT, OTS, SEC \\
\hline poor & high & SAT, OTS, SEC \\
\hline poor & high & SAT, OTS, SEC \\
\hline poor & high & SAT, OTS, SEC \\
\hline fair & high & OTS, SEC \\
\hline poor & high & OTS, SEC \\
\hline fair & high & OTS, SEC \\
\hline fair & high & OTS, SEC \\
\hline fair $^{7}$ & medium & OTS, SEC \\
\hline poor & medium & OTS, SEC \\
\hline fair & high & OTS \\
\hline fair & medium & OTS \\
\hline fair & low & OTS \\
\hline
\end{tabular}

Table 1. List of the most important data needed to parameterise and evaluate Dynamic Green Ocean Models.

\footnotetext{
${ }^{1}$ poor: insufficient data to provide adequate constraints; medium: some data, but insufficient coverage; good: good data coverage ( e.g. in space and time up to seasonal); very good: very good data coverage (e.g. in space and time over multiple years).

${ }^{2}$ These can be measured in the laboratory, mesocosm experiments, or in the field. Mesocosm and field data are usually not PFT-specific and are thus difficult to use to parameterize DGOMs. However mesocosm and field data can be used to evaluate model results.

${ }^{3}$ Models based on remote sensing data provide very good coverage of primary production, but they also need to be

evaluated with in situ data.

${ }^{4} \mathrm{pH}$ coverage is poor, but it can be estimated from measurements of other variables in the carbonate system.

${ }^{5}$ Measured separately for protozoans and metazoans.

${ }^{6}$ At different depth.

${ }^{7}$ Models based on remote sensing data provide very good coverage of primary production, but they also need to be evaluated with in situ data
} 
recorder (CPR) that collects data on plankton extending back to over 50 years in the North Atlantic, programmes such as the Atlantic Meridional Transect (www.amt-uk.org), which undertakes biological, chemical and physical oceanographic research during the annual return passage of research vessels between the UK and Antarctica, and the GO-SHIP initiative to include biological and bio-optical observations in the future (see paper by Hood et al., 2010). The Mirai BEAGLE circumpolar mission in the Southern Hemisphere represented a first for observations of many biological properties in some of the areas covered, and led to novel results regarding the distribution of ecotypes of Prochlorococcus [1]. Existing and new partnerships with the shipping industry to collect data from areas that would otherwise be under-sampled or not sampled at all, are also an important development (papers by Hydes and colleagues, Reid et al., 2010), from the perspective of modellers. Underway transects bridge the gaps in coverage (temporal and spatial) between time-series at fixed locations and repeat full water-column hydrography sections.

\subsection{Buoys and Gliders}

Drifting buoys such as Argo (Roemmich et al., 2010), with their global coverage, provide precious watercolumn data for the evaluation of model outputs. Other efforts useful to model evaluation include efforts to extend Argo-type of buoys to include bio-optical sensors (Claustre et al., 2010), and potentially also nutrients, oxygen and carbon [12], and data from the Ocean Tracking Network (O'Dor et al., 2010), which use sensors mounted on marine animals to collect data from hot productivity areas and areas that would otherwise be inaccessible.

\subsection{Oceanic time Series}

The ability to describe the temporal evolution of ecosystem variables is a requisite feature of all models designed to address climate-related issues. DGOMs need to reproduce the spatial mean fields of various PFTs as well as their temporal evolution and variability. Long-term and high-frequency time-series observations at a range of ocean environments, such as from the Hawaii Ocean Time-Series (HOT) and the Bermuda Atlantic Time-Series Study (BATS), are crucial for evaluating time- and depth-dependent variations in biological and biogeochemical properties [2]. The combination of autonomous, moored, observations with repeat visits of research vessels at these sites make it possible to measure a more complete suite of observations than would be possible from automatic systems alone. The coordination of open-ocean time series stations through OceanSITES, and efforts to sustain biological and bio-geochemical time series stations over long periods are therefore a very welcome development (see paper by Send et al., 2010). Coastal time series stations networked that provide ecosystem-related data (see paper by Groom et al., 2010) are also very useful for the evaluation of DGOMs in coastal areas. It is extremely important to maintain existing time-series stations (both open-ocean and coastal), and to initiate new time-series stations in different bio-geochemical environments, especially at high latitudes.

\subsection{Atmospheric time series}

Time series of atmospheric $\mathrm{CO}_{2}$ and $\mathrm{O}_{2}$ concentration combined with inverse modelling methods can provide important information on global and regional fluxes over the ocean. Their major advantage is that they can integrate over large areas (typically 1000-3000 km) and thus one single station can provide continuous information on a large oceanic region. $\mathrm{CO}_{2}$ can be used to estimate trends in the oceanic $\mathrm{CO}_{2}$ fluxes, so far over the Southern Ocean only [8]. $\mathrm{O}_{2}$ combined with $\mathrm{CO}_{2}$ can be used to detect variability of oceanic $\mathrm{O}_{2}$ [4] globally or regionally [14].

\section{PRIORITIES}

The existing observational coverage and its relevance to DGOMs are summarized in Tab. 1. Priorities for each data type are assigned here based on the sensitivity of model experiments done so far, and on the relevance of the results for the interactions with climate. The most important data needs to build and evaluate the mean state of models are:

- Global and regional biomass concentration in carbon units for the important plankton types for all seasons. Most data on the concentration of plankton are collected in abundance units (individuals per volume), whereas the models need to know the carbon content of biomass. Data can be converted if the species and individual average size are known [9]. The carbon concentration of some plankton types (bacteria, and meso- and macrozooplankton) exist with some global coverage but no seasonal information. For most plankton types information is completely missing (Tab. 1).

- Growth rates as a function of temperature, and to a lesser extent light and nutrient or food concentration. Model results are particularly sensitive to the parameterization of growth rates, and to the relative growth rates of phytoplankton, zooplankton, and bacteria. The dependence on temperature, light and nutrient or food is particularly important in a changing environment. 
The dependence to temperature is very different between plankton types, and consequently has high priority.

- Export of particulate organic carbon (POC), and to a lesser extent export of $\mathrm{CaCO}_{3}$, primary and secondary production. Changes in POC export are directly driven by changes in ecosystem fluxes. POC export is the biological flux that is most directly linked to the oceanic $\mathrm{CO}_{2}$ sink on a decadal time scale. The export of $\mathrm{CaCO}_{3}$ influences the vertical gradient of alkalinity, which also has an impact on $\mathrm{CO}_{2}$. Primary and secondary production are the underlying drivers of POC export, and are also important to support upper trophic levels.

The most important data needs to evaluate the response of models to climate and other environmental changes are:

- Decadal trends in surface ocean $\mathrm{pCO}_{2}$ for all seasons. Surface ocean $\mathrm{pCO}_{2}$ provides an integrated measure of biogeochemical changes in the surface ocean. Trends in surface ocean $\mathrm{pCO}_{2}$ are extremely valuable to test the sum of the physical and biogeochemical interactions and their response to change. The existing data provide coverage to estimate $\mathrm{pCO}_{2}$ trends over $\sim 25 \%$ of the ocean surface [16]. The seasonal trends provide information on the contribution of biological processes to changes, but they are only available in a few regions at present.

- Decadal trends in sub-surface $\mathrm{O}_{2}$ concentration. $\mathrm{O}_{2}$ changes in the sub-surface $(100-1000 \mathrm{~m})$ provide information on the relative importance of physical and biological processes in driving biogeochemical changes. It is thus a strong diagnostic of model performance. $\mathrm{O}_{2}$ changes can be measured directly in situ or from atmospheric $\mathrm{O}_{2} / \mathrm{N}_{2}$ ratios which provide integrated changes for a large oceanic region (typically 2000-5000 $\mathrm{km}$ in horizontal extent).

From the modelling perspective, a global coverage is essential to evaluate the model mean state, while repeated measurements for all seasons are most useful to evaluate the model response to environmental change. To obtain a global coverage with seasonal resolution, remote sensing, repeat sections and buoys and gliders are most appropriate. These platforms as well as time series stations (both oceanic and atmospheric) can provide information to evaluate the model's response to environmental change if they are sustained for multiple years to decades. Both a global coverage and repeated observations can only be obtained by a mix of platforms. Targeted laboratory experiments are essential to quantify PFT rates.
DGOMs could evolve in several directions. Several of the recognized important PFTs described in Section 2 could be split into sub-groups. New groups may emerge with new observations or with efforts to link biogeochemical cycles to higher trophic levels. Some DGOMs have already begun to assimilate observations, which require information on rates as well as biomass. The data requirements highlighted here are specifically addressed to the current generation of DGOMs and would be used to ensure that the rates used in current models are realistic [7] and [5], and that the models respond correctly to environmental changes. The data needs highlighted here will meet the requirements of future models as long as the primary information regarding the species sampled is preserved.

\section{CONCLUDING REMARKS}

Vast areas of the ocean remain completely un-sampled for many biological properties. Where observations do exist, they are poorly resolved with respect to seasons and multi-year variability and trends. Technological advances now make it possible to routinely observe many key biological variables that are essential to model ecosystem variability and vulnerability in a changing climate and potential feedbacks from ecosystem to climate. It is essential that these key variables form part of a sustained, integrated, global observation system. Such enhanced observations have to be complemented by parallel efforts to synthesize existing data, and to make the data readily available to users [9]. Synthesis products of PFT biomass and rates would be useful beyond the modelling community. Synthesis products could provide information on ecosystem interactions, and help detect the impact of climate and other environmental changes on ecosystems directly, including the potential for abrupt or dangerous changes.

This paper was led by the Green Ocean Consortium (http://lgmacweb.env.uea.ac.uk/green_ocean) and by the participants of the MARine Ecosystem Model Intercomparison Project (MAREMIP).

\section{REFERENCES}

1. Bouman, A.B., Ulloa, O., Scanlan, D., Zwirglmaier, C., Li, W.K.W., Platt, T., Stuart, V., Barlow, R., Leth, Ole, Clementson, L., Lutz, V., Fukasawa, M., Watanabe, S. \& Sathyendranath, S. (2006). Oceanographic Basis of the Global Surface Distribution of Prochlorococcus Ecotypes. Science 312, 918-921.

2. Ducklow, H., Doney, S.C. \& Steinberg, D.K. (2009). Contributions of Long-Term Research and Time-Series Observations to Marine Ecology and Biogeochemistry. Ann. Rev. Mar. Sci. 1, 279-302. 
3. Friedrichs, M.A.M. and the PPARR Team (2009). Assessing the Uncertainties of Model Estimates of Primary Productivity in the Tropical Pacific Ocean. $J$. Marine Syst. 76, doi:10.1016/j.jmarsys.2008.05.010.

4. Hamme, R.C. \& Keeling, R.F. (2008). Ocean Ventilation as a Driver of Interannual Variability in Atmospheric Potential Oxygen. Tellus-B 60, 706-717.

5. Hood, R.A., Laws, E.A., Armstrong, R.A., Bates, N.R., Brown, C.W., Carlson, C.A., Chai, F., Doney, S.C., Falkowski, P.G., Feely, R.A., Friedrichs, M.A.M., Landry, M.R., Moore, J.K., Nelson, D.M., Richardson, T.L., Salihoglu, B., Schartau, M., Toole, D.A. \& Wiggert, J.D. (2006). Pelagic Functional Group Modeling: Progress, Challenges and Prospects. DeepSea Res. II: 53, 459-512.

6. IOCCG (2008). Why Ocean Colour? The Societal Benefits of Ocean-Colour Technology. Platt, T., Hoepffner, N., Stuart, V. and Brown, C. (eds), Reports of the International Ocean-Colour Coordinating Group, No. 7, IOCCG, Dartmouth, Canada.

7. Le Quéré, C., Harrison, S.P., Prentice, I.C., Buitenhuis, E.T., Aumont, O., Bopp, L., Claustre, H., da Cunha, L.C., Geider, R., Giraud, X., Klaas, C., Kohfeld, K.E., Legendre, L., Manizza, M., Platt, T., Rivkin, R.B., Sathyendranath, S., Uitz, J., Watson, A.J. \& WolfGladrow, D. (2005). Ecosystem Dynamics Based on Plankton Functional Types for Global Ocean Biogeochemistry Models. Glob. Change Biol. 11, 2016-2040.

8. Le Quéré et al. (2007). Saturation of the Southern Ocean $\mathrm{CO}_{2}$ Sink Due to Recent Climate Change. Science 316, $1735-1738$

9. Le Quéré, C. \& Pesant, S. (2009). Plankton Functional Types in a New Generation of Biogeochemical Models. EOS Trans. AGU 90(4), 30-31.

10. Mannino, A., Russ, M.E. \& Hooker, S.B. (2008). Algorithm Development for Satellite-Derived Distributions of DOC and CDOM in the U.S. Middle Atlantic Bight. J. Geophys. Res. doi:10.1029/2007JC004493.

11. Nair, A., Sathyendranath, S., Platt, T., Morales, J., Stuart, V., Forget, M.-H., Devred, E. \& Bouman, H. (2008). Remote Sensing of Phytoplankton Functional Types. Remote Sens. Environ. 112, 3366-3375.

12. Nicholson et al. (2008). Net Community Production in the Deep Euphotic Zone of the Subtropical North Pacific Gyre from Glider Surveys. Limnol. Oceanogr. 53, 2226-2236.

13. Platt, T. \& Sathyendranath, S. (2008). Ecological Indicators for the Pelagic Zone of the Ocean. Remote Sens. Environ. 112, 3426-3436.
14. Rödenbeck, C., Le Quéré, C., Heimann, M. \& Keeling, R. (2008). Interannual Variability in Oceanic Biogeochemical Processes Inferred by Inversion of Atmospheric $\mathrm{O}_{2} / \mathrm{N}_{2}$ and $\mathrm{CO}_{2}$ Data. Tellus 60B, 685705.

15. Stramska, M. \& Stramski, D. (2008). Variability of Particulate Organic Carbon Concentration in the North Polar Atlantic Based on Ocean Color Observations with Sea-Viewing Wide Field of View Sensor (SeaWiFS). J. Geophys. Res. doi:10.1029/2004JC002762.

16. Takahashi, T., et al. (2009). Climatological Mean and Decadal Changes in Surface Ocean pCO2, and Net SeaAir CO2 Flux over the Global Oceans. Deep-Sea Res. II, doi:10.1016/j.dsr2.2008.12.009. 